\title{
USE OF ACOUSTIC EMISSION FOR TESTING RESISTANCE OF HOOVES
}

\author{
Petr Dostál ${ }^{1}$, Zdeněk Havlíček² $^{2}$ Lucie Kratochvílová $^{2}$
}

\begin{abstract}
'Department of Technology and Automobile Transport, Mendel University in Brno, Zemědělská 1, 61300 Brno, Czech Republic

${ }^{2}$ Department of Morphology, Physiology and Animal Genetics, Mendel University in Brno, Zemědělská 1, 61300 Brno, Czech Republic
\end{abstract}

\begin{abstract}
DOSTÁL PETR, HAVLÍČEK ZDENĚK, KRATOCHVÍLOVÁ LUCIE. 2018. Use of Acoustic Emission for Testing Resistance of Hooves. Acta Universitatis Agriculturae et Silviculturae Mendelianae Brunensis, 66(1): 0029-0033.

This paper deals with the possibility of using an acoustic emission method for testing tensile strength of hooves. By using the acoustic emission (AE) method, we are able to locate degraded areas in hooves and then estimate the extent of degradation. In the experimental part, a sensor was used to record the emission signals, the measured data were processed and analysed, and the response of hooves to the applied mechanical load over time was monitored. Altogether, three samples were tested on the Zwick Z050/TH 3A materials testing machine and simultaneously the acoustic emissions were measured during testing.
\end{abstract}

Keywords: hooves, locate degraded areas, acoustic emission, quality of hooves, animal genetics

\section{INTRODUCTION}

The current problem of cloven hoof diseases is very serious in our practical conditions, because with the rising yields of cattle there is a greater incidence of diseases of the limbs (Havlíček, 2014). The hoof diseases are some of the most common diseases in dairy cows. The scope of this disease depends on many factors in cattle, including nutrition and resulting metabolic disorders, technology and zoohygiene of stabling, genetic predisposition of animals, and last but not least, the hoof care.

The hoof care is understood as a timely and effective treatment of limping cows and the prevention of the onset of hoof diseases. Hoof disinfection is an important precautionary measure as well as bathing and treatment of hooves, which form a basis of health and high production of cattle. We encounter disease of hooves in cattle housed in tie-stall barns, where the movement of animals is considerably limited. Every disease of hooves means economic loss as in limping cows there is a significant reduction of feed intake and a reduction of milk production, metabolic disorders occur, while reproductive parameters of the herd deteriorate (Havlíček, 2014). To evaluate the quality of hooves under tensile stress, acoustic emission can be used.

Acoustic emission is a physical phenomenon during which we observe acoustic signals emitted by a mechanically or thermally stressed body, as well as a diagnostic method based on this phenomenon (Grosse et al., 2003). Current acoustic methods are based on accurate measurement procedures. Acoustic emission is one of the passive incoherent methods which use gradual wave pulses. Acoustic emission signals accompany dynamic processes in the material and manifest themselves as gradual elastic wave movement. The source is the released energy in the material. This process accompanies deformation, fracture, and phase transformations in the material. The acoustic emission does not affect the measured object, but it provides integral information about the dynamic state of the material (Rao, 1990). The method of acoustic emission can be used in agricultural practice to determine the occurrence and spread of cracks in hooves and change in the hoof suppleness, and to reveal the 
formation of deformation zones before cracking of the hoof, and so on. From the physical point of view, however, acoustic emission still includes some unexplained facts.

The acoustic emission method is based on physical measurements of elastic and traction waves propagating through the object material or on its surface. These stress waves are generated with the occurrence of plastic deformations in the material that is exposed to external forces (mechanical stress) (Miller et al., 2005). For the estimating of the damping magnitude in practice, basic calibration source of AE emissions, referred to as the Pen Test (Scruby, 1987), is commonly used. This form of testing represents a sudden quantum mitigation of the force affecting the object's surface in the perpendicular direction, resulting in a sharp pulse. The Pen Test is used to measure the damping and velocities of wave propagation in a given material, as well as to calibrate the $\mathrm{AE}$ sensors, or to express the intensity of $\mathrm{AE}$ sources related to the Pen Test (Yonn et al., 1995). The whole process of emission and detection of AE involves several procedures including the acoustic emission event, propagation of tensile waves from the source to the sensor, detection of tensile waves using the sensor and transformation to electrical signal, and final estimate of the resulting electrical signal of AE using a measuring device (Dickinson, 1990).

\section{MATERIALS AND METHODS}

For the experimental part, 20 verification measurements have been realized. Three samples of cattle hooves were chosen which best corresponded to the required parameters for static tensile stress. Measuring systems used for this experiment included Zwick Z050/TH3A (Fig. 1) materials testing machine and AE XEDO, gain $50 \mathrm{~dB}$, sensor IDK-09, and preamplifier $35 \mathrm{~dB}$. The sensor was attached by a special clip, while ultrasonic gel was applied to the contact surfaces. The hooves tested were subjected to tensile stress.

The stress testing process was monitored using an acoustic emission apparatus in an accredited laboratory. To measure this specific material, it is necessary to deal with following variables:

- production of standardized samples for a given type of test,

- production of specific preparations for fastening samples into the testing machine,

- modification of piezoelectric sensors and acoustic emission,

- gaining detailed parameters of the test material including age, density, and moisture content.

The first experiment verified the measurability of acoustic emission signals on the hooves in the tensile tests. For further verification measuring of the material during the tensile tests, it is essential to follow the already suggested method.

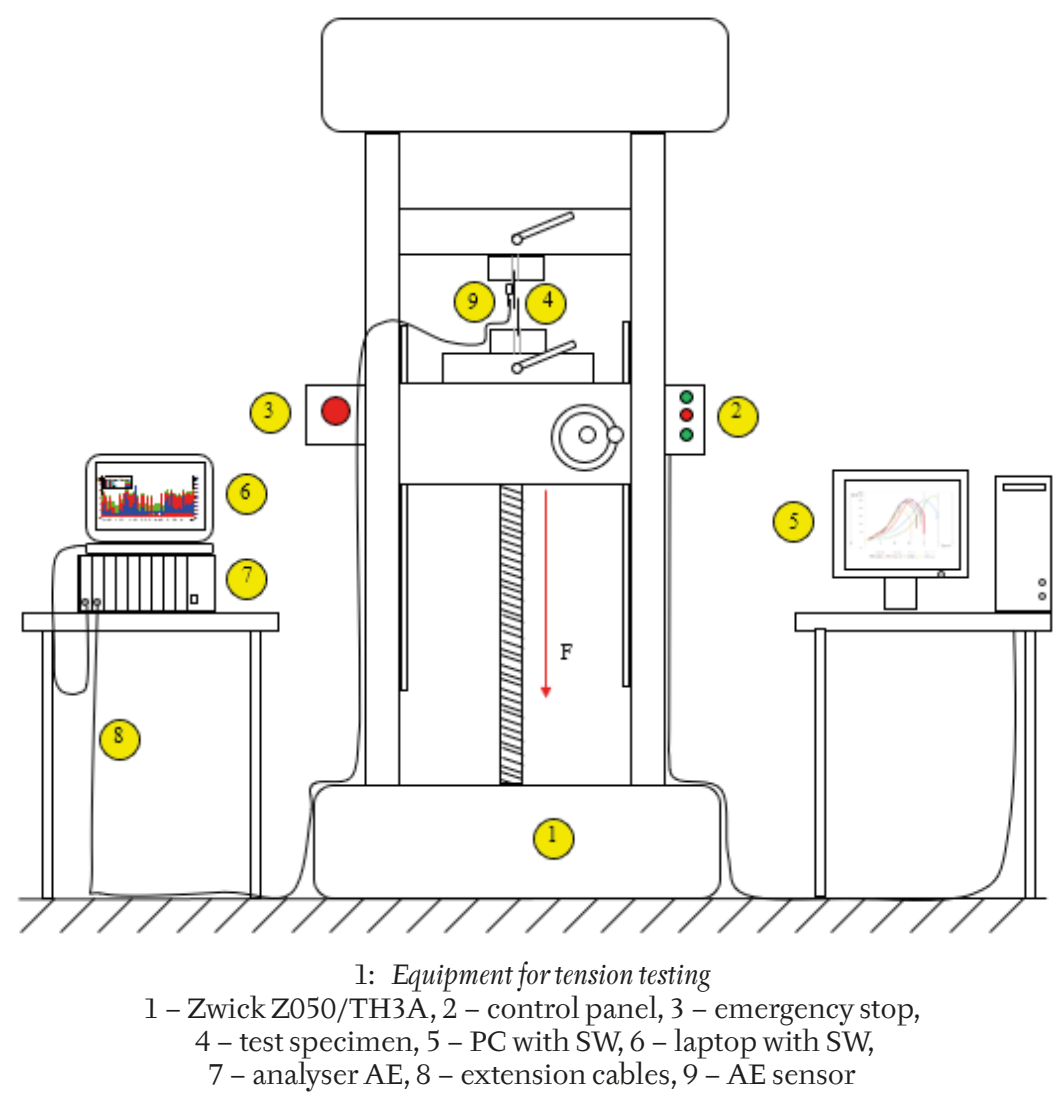


Load conditions were synchronized via TestExpert 11.02 software by Zwick Roell AG, Ulm, Germany. Samples were clamped into self-locking jaws. Tensile stress was measured by a load sensor of $50 \mathrm{kN}$ at a constant speed of $5 \mathrm{~mm} / \mathrm{min}$ until the sample failed. Sample failure was defined by a significant decrease in force along with a visible sign of sample failure.

\section{RESULTS AND DISCUSSION}

The tensile strength test in hooves was monitored by measuring the acoustic emission. The basic factor in the experiments is calibration of the sensitivity of the measuring device. During signal recording, its intensity sharply shifts and settings covering the broadest spectrum of emitted signals need to be calibrated. This results in protection from
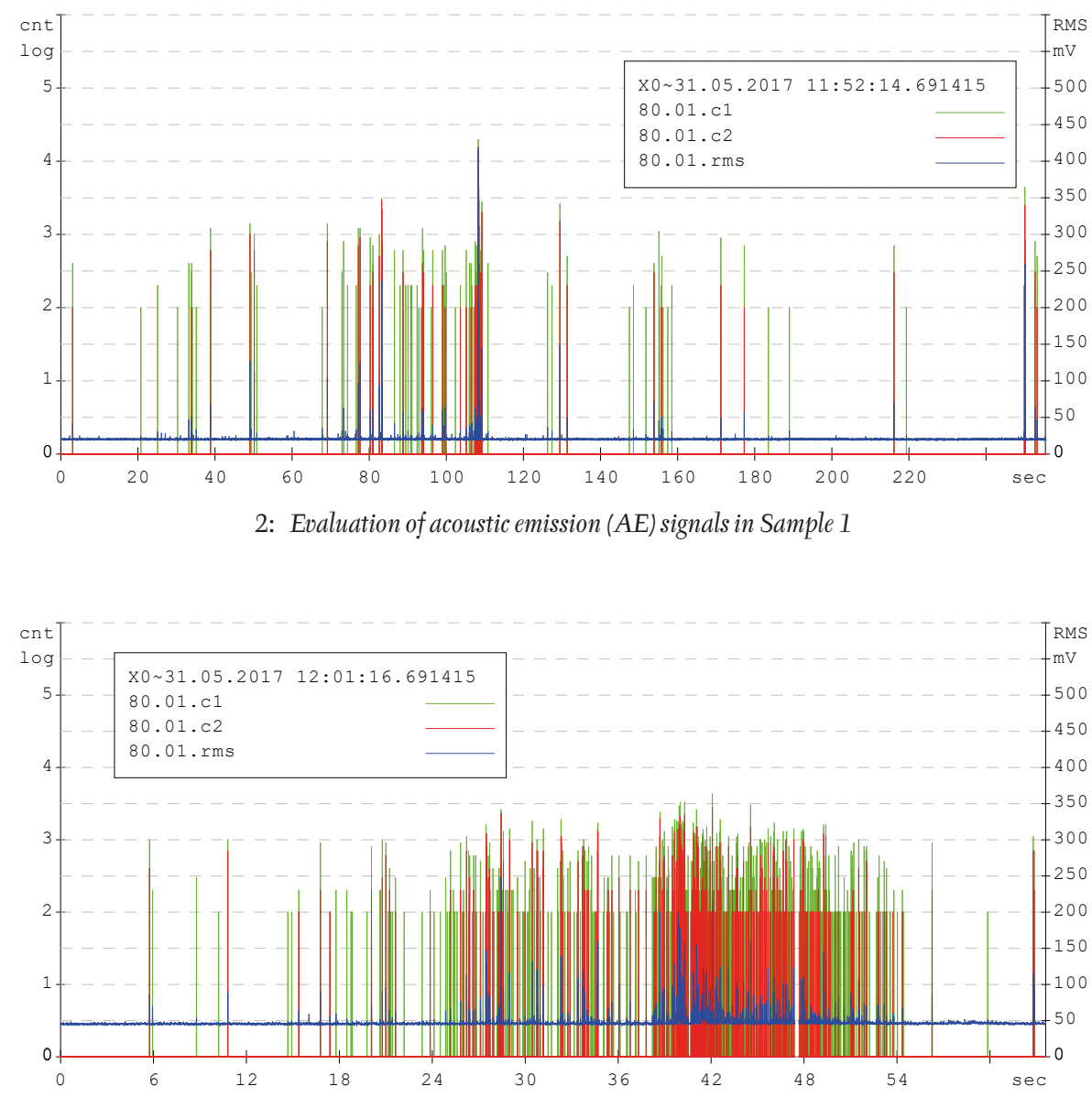

3: Evaluation of acoustic emission (AE) signals in Sample 2

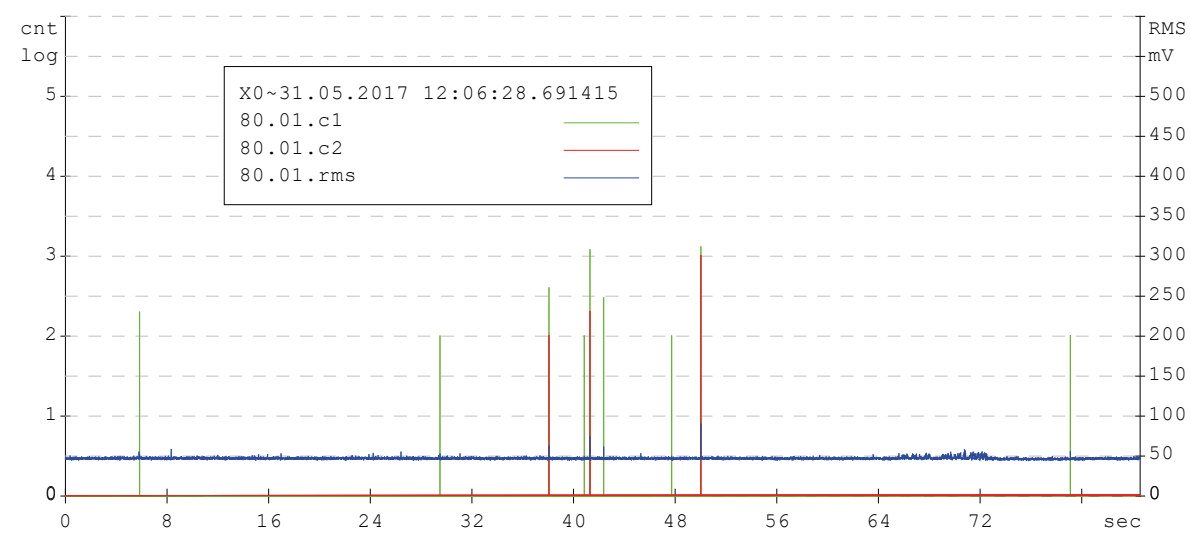

4: Evaluation of acoustic emission (AE) signals in Sample 3 


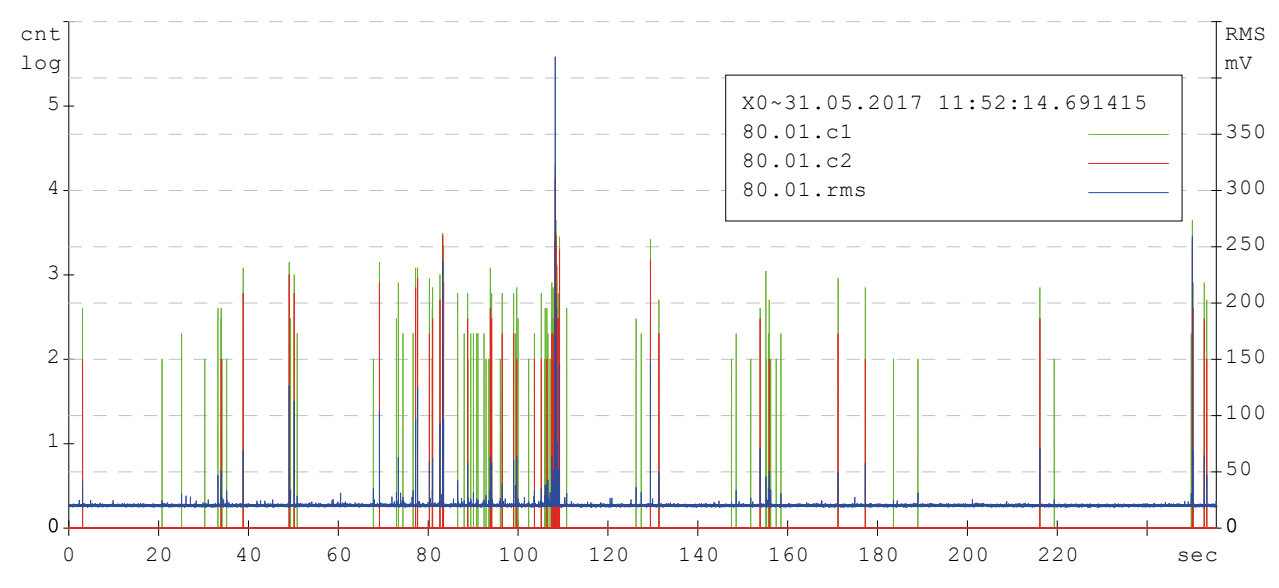

5: AE-Max RMS $450 m$ V for Sample 1
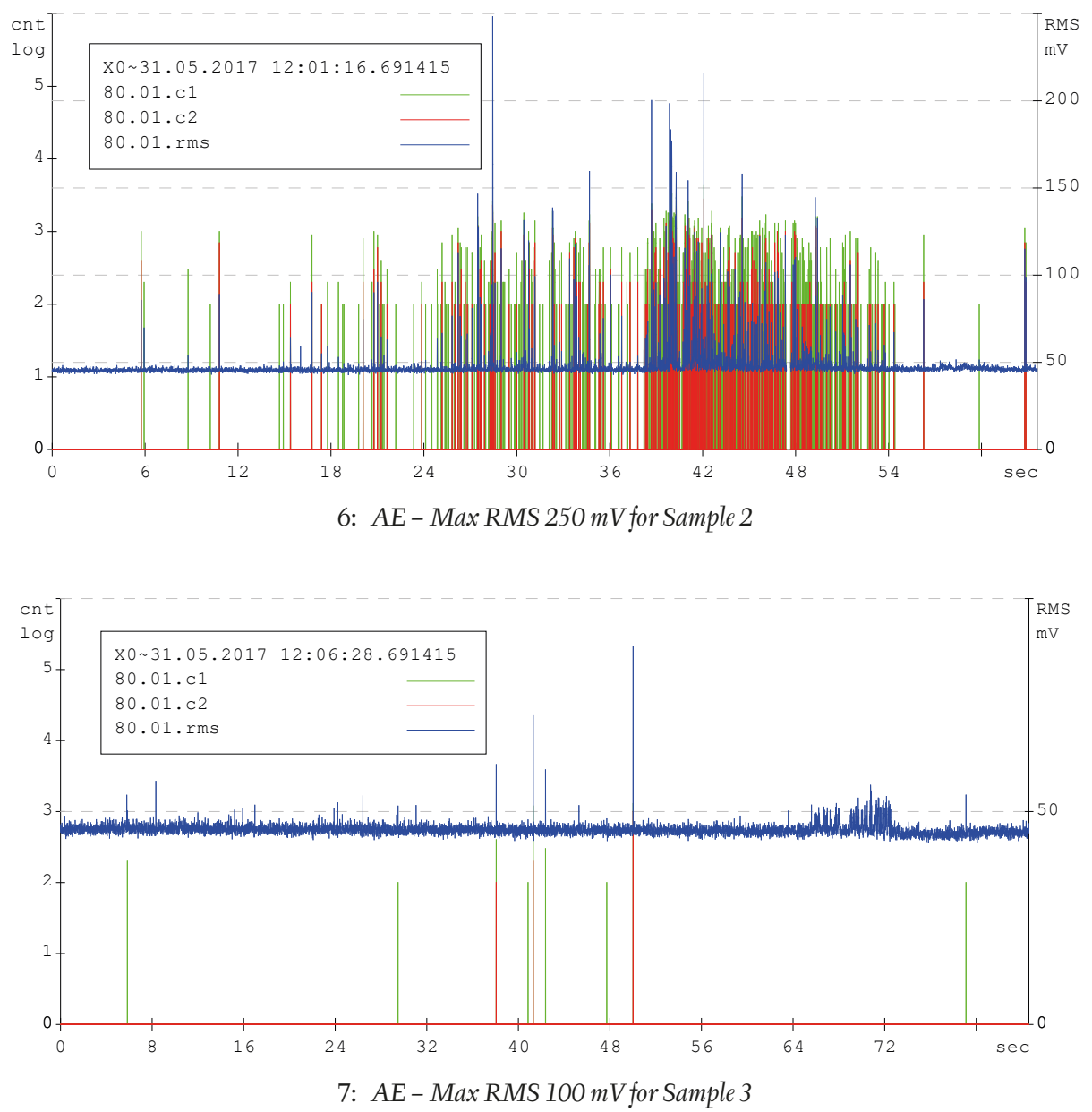

excessive damping or the opposite transition out of the measuring range. The obtained results show that the method of measurement of acoustic emission is suitable for the detection of initial structural changes in the hoof material. Individual conditions of hoof damage were detected. When comparing the sample in the tensile test, it is clear that the results do not show the same variability.
Figs. 2, 3, and 4 show the counts of acoustic emission signal exceedance where the sensor was placed on the samples. The graphs contain the basic description and identification of test samples. The $\mathrm{X}$ axis represents the time course of the test, while the left $Y$ axis indicates the intensity of the acoustic emission in the logarithmic scale of the energy level (counts). The right $\mathrm{Y}$ axis represents the mean 
quadratic value of the signal. The red lines represent the temporary dependence of localized events of acoustic emission. The green lines describe the temporary dependence of the total amount of acoustic emission. The blue lines show the course of the signal's effective value (the medial quadratic level of the detected signal).

Counts are especially effective to cover a wide range of measured amplitudes, while only the levels showing the greatest change during the measurement can be displayed. Another parameter that can be analysed in the time range is RMS. The RMS provides sufficiently stable information in a broad energy spectrum (Fasana, 2007). AE matches can be described in a time range with following important parameters: number of emission events (hits), cumulative count or maximum amplitude. Another phenomenon that is worth attention is the specific course of RMS during the experiment. At some point, there are specific drops in the RMS levels, indicating a change in AE activity in another upward trend.

In the initial phase of the measurement (Figs. 5, 6 and 7), from approximately the $10^{\text {th }}$ second, it is possible to recognize a rather dramatic increase in the signal. The occurrence of a frequent increase in the signal is recorded in this area, which is attributed to the formation of traces along with the onset of continuous hoof destruction, namely the occurrence of micro cracks in hooves. When the load is increased from the $25^{\text {th }}$ second, the hooves begin to deform differently. This period is gradually expanding to a point where the signal shows oscillation of the maximum value. During the cracks propagation in the perpendicular direction, the hoof eventually breaks, which contributes significantly to the final collapse of the composite structure. The sample collapse corresponds to the end point of the RMS curve, indicating the complete halt of the measuring instrument in the range of the terminal block load.

\section{CONCLUSION}

In conclusion, acoustic emission can be used to assess the hoof quality under tensile stress. The evidence is that when the force (stress) changes, there is an emission of acoustic signals that can be assigned to internal changes in the hooves. In all three samples, the acoustic emission signal was positively recognized and correlated with the structural defects generated in the hooves during the test. According to a number of other AE applications, it is convincing that non-destructive AE measurements provide invaluable information about processes that occur in the internal structure of hooves. AE therefore shows its value in practical use in the agricultural sector. AE should be used in the agricultural sector for early detection of undesirable changes in hooves.

Acknowledgment

The research has been supported by the TP 6/2017 project: Defectoscopic quality assessment of technical and organic materials; financed by IGA AF MENDELU.

\section{REFERENCES}

DICKINSON, J. T. 1990. Fracto-emission. Non-destructive testing of fibre-reinforced plastics composites. New York, USA: Sole distributor in the USA and Canada, Elsevier Science Pub. Co., pp. 429-475.

FASANA A. AND GARIBALDI, L. 2007. Measurement of Acoustic Emission Signals: Influence of the Couplant. Key Engineering Materials, Vol. 347, pp. 375-380.

HAVLÍČEK, Z. 2014. Zdravotníbezpečnost krmiv, stájovéprostředía výskyt mastitid [online]. Mendelova univerzita. Brno: Mendelova univerzita, [cit. 2017-08-17]. ISBN 978-80-7509-221-2 49. at: http://web2.mendelu. cz/af_291_projekty/files/21/21-zdravotni_bezpecnost_krmiv_stajove_prostredi_a_vyskyt_mastitid.pdf

MILLER R. K. and HILL, E. V. K. 2005. Nondestructive testing handbook: acoustic emission testing. Third edition. United States of America. American Society for Nondestructive Testing.

RAO, A. 1990. Acoustic emission and signal analysis, Defence Science Journal, vol. 40, no. 1, p.55.

SCRUBY, C. B. 1987. Instrument Science and Technology. An Introduction to Acoustic Emission. Journal of Physics E, Scientific Instruments.

YOON, D. J., KWON O. Y., CHUNG, M. H. and KIM, M. H., 1995. Early Detection of Damages in Journal Bearings by Acoustic Emission Monitoring. Journal of acoustic emission, CA, USA: acoustic emission group. Etatsunis, Vol. 13, pp. 1-10. 